\title{
Three eremophilane derivatives, MBJ-0011, MBJ-0012 and MBJ-0013, from an endophytic fungus Apiognomonia sp. f24023
}

\author{
Teppei Kawahara ${ }^{1}$, Masashi Itoh ${ }^{2}$, Miho Izumikawa ${ }^{1}$, Noriaki Sakata ${ }^{2}$, Toshio Tsuchida $^{2}$ \\ and Kazuo Shin-ya ${ }^{3}$
}

The Journal of Antibiotics (2013) 66, 299-302; doi:10.1038/ja.2013.13; published online 27 March 2013

Keywords: Apiognomonia; eremophilane; terpenoid

\begin{abstract}
Eremophilane sesquiterpenoids are well-known cytotoxic, phytotoxic, mycotoxic and phytohormonic secondary metabolites that are obtained from fungi and higher plants. ${ }^{1-9}$ During this half decade, we have constructed the library of isolated natural products $(\mathrm{CB}$ library), mostly of microbial origin, with the aim of efficiently implementing several biological screenings. ${ }^{10}$ In the course of our screening for novel natural compounds, which will provide new scaffolds for drug development, we have developed the advanced compound-identification system designated as 'MBJ's special selection' and have succeeded in discovering many new natural compounds. Among them, eremophilane derivatives MBJ-0011 (1), MBJ-0012 (2) and MBJ-0013 (3) were discovered as cytotoxic compounds from an endophytic fungus Apiognomonia sp. f24023 (Figure 1). The fermentation, isolation, structural elucidation and preliminary biological activities of 1-3 are described herein.
\end{abstract}

The producing microorganism, Apiognomonia sp. f24023, classified based on partial sequence of the D1/D2 region of the $28 \mathrm{~S}$ ribosomal RNA gene (data not shown), was isolated from a plant growing in Iwata, Shizuoka Prefecture, Japan. The strain was cultivated in $250-\mathrm{ml}$ Erlenmeyer flasks, each containing $25 \mathrm{ml}$ of a seed medium consisting of potato starch (Tobu Tokachi Nosan Kako Agricultural Cooperative Assoc., Hokkaido, Japan) 2\%, glucose (Junsei Chemical, Tokyo, Japan) $2 \%$, soybean powder (Honen SoyPro, J-Oil Mills, Tokyo, Japan) $2 \%, \mathrm{KH}_{2} \mathrm{PO}_{4} 0.1 \%$, and $\mathrm{MgSO}_{4} \cdot 7 \mathrm{H}_{2} \mathrm{O} 0.05 \%$. The flasks were shaken on a rotary shaker $\left(220\right.$ r.p.m.) at $25^{\circ} \mathrm{C}$ for 3 days. Aliquots $(0.5 \mathrm{ml})$ of the broth were transferred to $500-\mathrm{ml}$ Erlenmeyer flasks containing $50 \mathrm{ml}$ of a production medium consisting of fructose (Junsei Chemical) 1.5\%, xylitol (Junsei Chemical) 1.5\%, maltose monohydrate (Junsei Chemical) $1.5 \%$, galactose (Wako Pure Chemical Industries, Osaka, Japan) $1.5 \%$, soybean powder $2 \%$, gluten meal (Nihon Shokuhin Kako, Tokyo, Japan) 1\%, yeast extract powder (Oriental Yeast, Tokyo, Japan) $0.5 \%, \mathrm{ZnSO}_{4} \cdot 7 \mathrm{H}_{2} \mathrm{O} 0.02 \%$,
$\mathrm{MgSO}_{4} \cdot 7 \mathrm{H}_{2} \mathrm{O} \quad 0.02 \%, \mathrm{FeSO}_{4} \cdot 7 \mathrm{H}_{2} \mathrm{O} \quad 0.02 \%$, and 3-indoleacetic acid $0.002 \%$, pH 6.0 (adjusted before sterilization), and were cultured on a rotary shaker ( 220 r.p.m.) at $25^{\circ} \mathrm{C}$ for 4 days. After fermentation, the whole culture broth (21) was extracted with an equal volume of $n$ $\mathrm{BuOH}$. The $n-\mathrm{BuOH}$ extract was partitioned between $\mathrm{CHCl}_{3}$ $(350 \mathrm{ml} \times 3)$ and brine $(350 \mathrm{ml})$. The organic layer was evaporated and the concentrate $(868 \mathrm{mg})$ was fractionated using mediumpressure silica gel chromatography (Purif-Pack SI-30, Shoko Scientific, Yokohama, Japan) with the gradient system of $n$-hexane-EtOAc $\left(0-25 \%\right.$ EtOAc) followed by the stepwise solvent system of $\mathrm{CHCl}_{3}-$ $\mathrm{MeOH}(0,2,5,10,20,30$ and $100 \% \mathrm{MeOH})$. Compound 1 (2.5 mg) was obtained after purification of the $2 \% \mathrm{MeOH}$ fraction $(21 \mathrm{mg})$ by reversed-phase HPLC using a CAPCELL PAK C18 MGII column $(5.0 \mu \mathrm{m}, 20$ i.d. $\times 150 \mathrm{~mm}$; Shiseido, Tokyo, Japan) with $60 \%$ aqueous $\mathrm{MeOH}$ containing $0.1 \%$ formic acid (flow rate: $10 \mathrm{ml} \mathrm{min}^{-1}$, retention time $(\mathrm{Rt})=19.5 \mathrm{~min})$. The $5 \% \mathrm{MeOH}$ fraction $(102 \mathrm{mg}$ ) was applied to reversed-phase medium-pressure column (Purif-Pack ODS-30, Shoko Scientific, Yokohama, Japan) and developed with the stepwise $\mathrm{H}_{2} \mathrm{O}-\mathrm{MeOH}$ solvent system (70, 80 and $\left.100 \% \mathrm{MeOH}\right)$. The $80 \% \mathrm{MeOH}$ eluate $(25.6 \mathrm{mg}$ ) was subjected to HPLC (CAPCELL PAK C18 MGII column, $70 \%$ aqueous $\mathrm{MeOH}$ containing $0.1 \%$ formic acid, flow rate: $\left.10 \mathrm{ml} \mathrm{min}^{-1}\right)$ to yield $2(17.2 \mathrm{mg}, \mathrm{Rt}=14.6 \mathrm{mim})$ and crude $3(8.3 \mathrm{mg}, \mathrm{Rt}=17.0 \mathrm{~min})$. The crude material containing 3 was then re-chromatographed with the same system to give pure 3 (1.2 mg, Rt = $17.0 \mathrm{~min})$.

MBJ-0011 (1) was isolated as a colorless amorphous solid: $[\alpha]^{27} \mathrm{D}$ +20 (c 0.13, MeOH); UV $\lambda_{\max } \mathrm{nm}(\log \varepsilon): 276$ (4.2) in $\mathrm{MeOH}$; IR (ATR) $v_{\max } 1650 \mathrm{~cm}^{-1}$ (unsaturated ketone). Its molecular formula was determined as $\mathrm{C}_{22} \mathrm{H}_{28} \mathrm{O}_{5}$ by $\mathrm{HR}$ electrospray ionization MS (HRESI-MS) $\left(m / z\right.$ 373.1994 $[\mathrm{M}+\mathrm{H}]^{+}$, calcd for $\left.\mathrm{C}_{22} \mathrm{H}_{29} \mathrm{O}_{5}: 373.2015\right)$. The planar structure was clarified by the series of $2 \mathrm{D}$ NMR analyses, including double quantum filtered COSY (DQF-COSY),

${ }^{1}$ Japan Biological Informatics Consortium (JBIC), Tokyo, Japan; ${ }^{2}$ Bioresource Laboratories, MicroBiopharm Japan (MBJ), Iwata, Shizuoka, Japan and ${ }^{3}$ National Institute of Advanced Industrial Science and Technology (AIST), Tokyo, Japan

Correspondence: Dr K Shin-ya, National Institute of Advanced Industrial Science and Technology (AIST), 2-4-7 Aomi, Koto-ku, Tokyo 135-0064, Japan.

E-mail: k-shinya@aist.go.jp

Received 30 October 2012; revised 16 January 2013; accepted 31 January 2013; published online 27 March 2013 
<smiles>[3H]C(C(=O)O[C@H]1C=CC2=CC(=O)[C@@H](C(=C)C)C[C@]2(C)[C@H]1C)C1CCC(=O)O1</smiles><smiles></smiles><smiles>CCOCCCN</smiles>

MBJ-0013 (3)

Figure 1 Structures of $1-3$.

heteronuclear single quantum coherence and constant-time heteronuclear multiple-bond correlation ${ }^{11}$ (CT-HMBC; Figures 2a and b). The ${ }^{13} \mathrm{C}$ and ${ }^{1} \mathrm{H}$ NMR data for $\mathbf{1}$ are listed in Table 1.

The structure determination of $\mathbf{1}$ was carried out by dividing it into two partial moieties on the basis of DQF-COSY and CT-HMBC as follows. The sequence from an oxymethine proton $\mathrm{H}-3\left(\delta_{\mathrm{H}} 5.38\right)$ to a methyl proton $\mathrm{H}_{3}-14\left(\delta_{\mathrm{H}} 0.99\right)$ through a methine proton $\mathrm{H}-4\left(\delta_{\mathrm{H}}\right.$ 1.88) was observed in the DQF-COSY. Long-range ${ }^{1} \mathrm{H}-{ }^{13} \mathrm{C}$ couplings from the methyl proton $\mathrm{H}_{3}-14$ to an oxymethine carbon $\mathrm{C}-3\left(\delta_{\mathrm{C}}\right.$ 74.0), a methine carbon $\mathrm{C}-4\left(\delta_{\mathrm{C}} 43.7\right)$ and a quaternary carbon $\mathrm{C}-5$ $\left(\delta_{\mathrm{C}} 37.9\right)$, and from a methyl proton $\mathrm{H}_{3}-15\left(\delta_{\mathrm{H}} 1.21\right)$ to $\mathrm{C}-4, \mathrm{C}-5$, a methylene carbon C-6 $\left(\delta_{\mathrm{C}} 39.6\right)$ and an olefinic quaternary carbon C-10 $\left(\delta_{\mathrm{C}} 160.1\right)$ revealed the sequence from C-3 to C- 6 as shown in Figure 2a. HMBC correlations from an olefinic methine proton $\mathrm{H}-2$ $\left(\delta_{\mathrm{H}} 6.01\right)$, which was spin coupled to an olefinic methine proton $\mathrm{H}-1$ $\left(\delta_{\mathrm{H}} 6.22\right)$, to $\mathrm{C}-4$ and the olefinic quaternary carbon $\mathrm{C}-10$, and from the olefinic proton $\mathrm{H}-1$ to $\mathrm{C}-3, \mathrm{C}-5$ and $\mathrm{C}-10$ established the sixmembered cyclic moiety. Long-range ${ }^{1} \mathrm{H}-{ }^{13} \mathrm{C}$ coupling from methylene protons $\mathrm{H}_{2}-6\left(\delta_{\mathrm{H}} 2.01\right.$ and 1.93$)$ to an $\alpha, \beta$-unsaturated ketone carbonyl carbon C-8 $\left(\delta_{\mathrm{C}} 198.5\right)$, which in turn long-range coupled to a methine proton $\mathrm{H}-7\left(\delta_{\mathrm{H}} 3.25\right)$, was observed. Together with these HMBC correlations, long-range couplings from an olefinic proton H-9 $\left(\delta_{\mathrm{H}} 5.80\right)$ to C-5, a methine carbon C-7 $\left(\delta_{\mathrm{C}} 50.6\right)$ and an olefinic carbon $\mathrm{C}-1\left(\delta_{\mathrm{C}} 129.6\right)$ revealed an 2-decalone moiety. Furthermore, long-range couplings from a methyl proton $\mathrm{H}_{3}-13\left(\delta_{\mathrm{H}} 1.72\right)$ to $\mathrm{C}-7$, an olefinic quaternary carbon $\mathrm{C}-11\left(\delta_{\mathrm{C}} 143.3\right)$ and an exomethylene carbon C-12 $\left(\delta_{\mathrm{C}} 115.0\right)$ established a 6-oxygenated 4,4a,5,6-tetrahydro-4a,5-dimethyl-3-(1-methylethenyl)-2(3H)-naphthalenone moiety (an eremophilane skeleton) as shown in Figure 2a.

The other substructure of $\mathbf{1}$ was elucidated as follows. A sequence from doublet methyl protons $\mathrm{H}_{3}-7^{\prime}\left(\delta_{\mathrm{H}} 1.25\right)$ to methylene protons $\mathrm{H}_{2}-5^{\prime}\left(\delta_{\mathrm{H}} 2.57\right.$ and 2.56) through a methine proton $\mathrm{H}-2^{\prime}\left(\delta_{\mathrm{H}} 2.77\right)$, an oxygenated methine proton $\mathrm{H}-3^{\prime}\left(\delta_{\mathrm{H}} 4.71\right)$ and methylene protons $\mathrm{H}_{2}-4^{\prime}\left(\delta_{\mathrm{H}} 2.38\right.$ and 1.96$)$ was established by the analysis of the DQFCOSY. Long-range ${ }^{1} \mathrm{H}-{ }^{13} \mathrm{C}$ couplings from $\mathrm{H}-3^{\prime}$ and $\mathrm{H}-5^{\prime}$ to an ester carbonyl carbon $\mathrm{C}-6^{\prime} \quad\left(\delta_{\mathrm{C}}\right.$ 176.1) revealed a $\gamma$-lactone moiety a
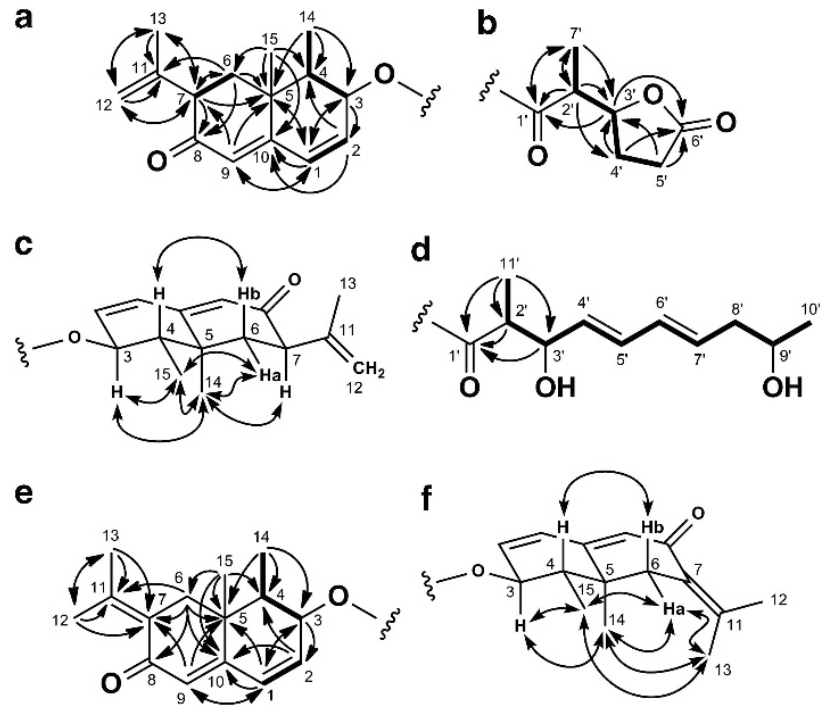

Figure 2 (a) Partial structure of $\mathbf{1}$ (sesquiterpenoid moiety). (b) Partial structure of 1 (tetrahydro- $\alpha$-methyl-5-oxo-2-furanacetic acid moiety). (c) Key NOESY correlations of $\mathbf{1}$. (d) Partial structure of 2. (e) Partial structure of 3. (f) Key NOESY correlations of 3. COSY and $\mathrm{HMBC}\left({ }^{1} \mathrm{H}\right.$ to $\left.{ }^{13} \mathrm{C}\right)$ correlations are shown as bold lines and solid arrows, respectively.

(Figure $2 \mathrm{~b}$ ). In addition to these correlations, a long-range coupling from the methyl proton $\mathrm{H}_{3}-7^{\prime}$ to an ester carbonyl carbon $\mathrm{C}-1^{\prime}\left(\delta_{\mathrm{C}}\right.$ 172.9) determined the presence of a tetrahydro- $\alpha$-methyl-5-oxo-2furanacetic acid moiety.

An ester linkage between the two partial structures was proved by an HMBC correlation from the low-field-shifted methine proton $\mathrm{H}-3$ by acylation to the ester carbonyl carbon $\mathrm{C}-1^{\prime}$. Therefore, the gross structure of $\mathbf{1}$ was determined as shown in Figure 1. The relative configuration of the sesquiterpenoid moiety of 1 was clarified by vicinal ${ }^{3} J_{\mathrm{H}, \mathrm{H}}$ values and NOESY correlations (Figure $2 \mathrm{c}$ ). The coupling constants of $\mathrm{H}-7(J=5.0$ and $14.0 \mathrm{~Hz})$ indicated that this proton had a pseudoaxial orientation. Furthermore, NOESY correlations between $\mathrm{H}-7$ and $\mathrm{H}_{3}-14$ and between $\mathrm{H}_{3}-14$ and $\mathrm{H}-3$ revealed that $\mathrm{C}-14$ and $\mathrm{H}-3$ are also pseudoaxial orientations. Furthermore, C-15 was determined to have pseudoequatorial orientation on the basis of a NOESY correlation between $\mathrm{H}_{3}-14$ and $\mathrm{H}_{3}-15$. Hence, the partial relative configuration of $\mathbf{1}$ was determined as shown in Figure 1.

MBJ-0012 (2) and MBJ-0013 (3) were isolated as colorless amorphous solids with optical rotations of $[\alpha]^{27}{ }_{\mathrm{D}}-26$ (c 0.43 , $\mathrm{MeOH})$ for 2 and $[\alpha]^{27}-54(c 0.06, \mathrm{MeOH})$ for 3 . They showed UV absorption maxima at $230(\log \varepsilon 4.5)$ and $275(\log \varepsilon 4.4) \mathrm{nm}$ for 2, and at $229(\log \varepsilon 4.4), 275(\log \varepsilon 4.3)$ and 310 (sh) nm for 3, suggesting the presence of similar unsaturated systems, and their IR spectra indicated the presence of unsaturated ketone $\left(1650 \mathrm{~cm}^{-1}\right)$ and hydroxy $\left(3300 \mathrm{~cm}^{-1}\right)$ functional groups. Their HR-ESI-MS spectra gave the same molecular formula of $\mathrm{C}_{26} \mathrm{H}_{36} \mathrm{O}_{5}$ (obsd: $\mathrm{m} / z 429.2649$ $[\mathrm{M}+\mathrm{H}]^{+}$for 2 and $\mathrm{m} / z$ 429.2666 $[\mathrm{M}+\mathrm{H}]^{+}$for 3, calcd for $\mathrm{C}_{26} \mathrm{H}_{37} \mathrm{O}_{5}$ : 429.2641).

The NMR data for $\mathbf{2}$ indicated that it had the same sesquiterpenoid moiety as $\mathbf{1}$, including the stereochemistry. The determination of the remaining substructure was carried out as follows (Figure 2d). Based on the analysis of the DQF-COSY, the ${ }^{1} \mathrm{H}$ sequence from methyl protons $\mathrm{H}_{3}-11^{\prime}\left(\delta_{\mathrm{H}} 1.18\right)$ to methyl protons $\mathrm{H}_{3}-10^{\prime}\left(\delta_{\mathrm{H}} 1.19\right)$ through a methine proton $\mathrm{H}-2^{\prime}\left(\delta_{\mathrm{H}} 2.62\right)$, an oxygenated methine proton $\mathrm{H}-3^{\prime}\left(\delta_{\mathrm{H}} 4.25\right)$, olefinic methine protons $\mathrm{H}-4^{\prime}\left(\delta_{\mathrm{H}} 5.59\right), \mathrm{H}-5^{\prime}\left(\delta_{\mathrm{H}}\right.$ 6.26), $\mathrm{H}-6^{\prime}\left(\delta_{\mathrm{H}} 6.11\right)$ and $\mathrm{H}-7^{\prime}\left(\delta_{\mathrm{H}} 5.73\right)$, methylene protons $\mathrm{H}_{2}-8^{\prime}$ 
Table $1{ }^{13} \mathrm{C}$ and ${ }^{1} \mathrm{H}$ NMR spectroscopic data for MBJ-0011 (1), MBJ-0012 (2) and MBJ-0013 (3)

\begin{tabular}{|c|c|c|c|c|c|c|}
\hline \multirow[b]{2}{*}{ Position } & \multicolumn{2}{|r|}{1} & \multicolumn{2}{|r|}{2} & \multicolumn{2}{|r|}{3} \\
\hline & $\delta_{C}$ & $\delta_{H}$, multiplicity $(\mathrm{J}$ in $\mathrm{Hz})$ & $\delta_{C}$ & $\delta_{H}$, multiplicity $(\mathrm{J}$ in $\mathrm{Hz})$ & $\delta_{C}$ & $\delta_{H}$, multiplicity $(\mathrm{J}$ in $\mathrm{Hz})$ \\
\hline 1 & 129.6 & $6.22, \mathrm{dd}(2.0,10.0)$ & 129.4 & $6.19, \mathrm{dd}(1.5,10.0)$ & 129.1 & 6.19, br d (10.0) \\
\hline 2 & 135.3 & $6.01, \mathrm{dd}(2.0,10.0)$ & 135.7 & $5.98, \mathrm{dd}(1.5,10.0)$ & 135.0 & 5.95, br d (10.0) \\
\hline 3 & 74.0 & 5.38, ddd $(2.0,2.0,10.0)$ & 73.5 & 5.37, br d (10.0) & 73.6 & 5.34, br d (9.0) \\
\hline 4 & 43.7 & $1.88, \mathrm{~m}$ & 43.7 & $1.87, \mathrm{~m}$ & 43.2 & $1.89, \mathrm{ovl}^{\mathrm{a}}$ \\
\hline 5 & 37.9 & & 37.9 & & 39.3 & \\
\hline 6 & 39.6 & 2.01, ovla $; 1.93$, ovl $^{\mathrm{a}}$ & 39.6 & $2.00, \mathrm{dd}(5.0,13.0) ; 1.93, \mathrm{dd}(13.0,13.0)$ & 39.5 & 2.93, d (13.0); 2.18, ovl ${ }^{\mathrm{a}}$ \\
\hline 7 & 50.6 & $3.25, \mathrm{dd}(5.0,14.0)$ & 50.6 & $3.24, \mathrm{dd}(5.0,13.0)$ & 126.8 & \\
\hline 8 & 198.5 & & 198.6 & & 191.0 & \\
\hline 9 & 125.3 & $5.80, \mathrm{~s}$ & 125.2 & $5.78, \mathrm{~s}$ & 127.6 & $5.79, \mathrm{~s}$ \\
\hline 10 & 160.1 & & 160.2 & & 158.0 & \\
\hline 11 & 143.3 & & 143.3 & & 146.3 & \\
\hline 12 & 115.0 & 4.99, br s; 4.86, br s & 114.9 & 4.99, br s; 4.85, br s & 23.3 & $2.16, \mathrm{~s}$ \\
\hline 13 & 19.8 & $1.72, \mathrm{~s}$ & 19.8 & $1.71, \mathrm{~s}$ & 22.9 & $1.88, \mathrm{~s}$ \\
\hline 14 & 10.3 & $0.99, \mathrm{~d}(7.0)$ & 10.2 & $0.98, d(7.0)$ & 10.3 & $1.02, \mathrm{~d}(7.0)$ \\
\hline 15 & 16.7 & $1.21, \mathrm{~s}$ & 16.7 & $1.20, \mathrm{~s}$ & 16.4 & $1.00, \mathrm{~s}$ \\
\hline 1 & 172.9 & & 175.2 & & 175.2 & \\
\hline 2 & 44.8 & $2.77, \mathrm{dq}(7.0,7.0)$ & 45.9 & $2.62, \mathrm{dq}(7.0,7.0)$ & 45.8 & 2.62 \\
\hline 3 & 80.6 & 4.71, ddd $(7.0,7.0,8.5)$ & 74.5 & $4.25, \mathrm{dd}(7.0,7.0)$ & 74.5 & $4.23, \mathrm{dd}(7.0,7.0)$ \\
\hline 4 & 25.4 & 2.38, dddd $(7.0,7.0,14.0,14.0) ; 1.96, \mathrm{~m}$ & 131.2 & $5.59, \mathrm{dd}(7.0,15.0)$ & 131.3 & $5.60, \mathrm{dd}(7.0,15.5)$ \\
\hline 5 & 28.5 & 2.57, ovla $; 2.56, \mathrm{ovl}^{\mathrm{a}}$ & 132.6 & 6.26, dd $(11.0,15.0)$ & 132.6 & 6.27, dd $(10.0,15.5)$ \\
\hline 6 & 176.1 & & 132.2 & $6.11, \mathrm{dd}(11.0,15.0)$ & 132.3 & $6.12, \mathrm{dd}(10.0,15.0)$ \\
\hline 7 & 12.6 & $1.25, \mathrm{~d}(7.0)$ & 131.6 & 5.73, ddd $(8.0,8.0,15.0)$ & 131.6 & 5.73, ddd $(7.0,7.0,15.0)$ \\
\hline 8 & & & 42.5 & $2.27, \mathrm{ovl}^{\mathrm{a}} ; 2.22, \mathrm{ovl}^{\mathrm{a}}$ & 42.5 & $2.28, \mathrm{ovl}^{\mathrm{a}} ; 2.22, \mathrm{ovl}^{\mathrm{a}}$ \\
\hline 9 & & & 67.3 & $3.84, \mathrm{~m}$ & 67.3 & $3.85, \mathrm{ddq}(1.0,6.0,7.0)$ \\
\hline 10 & & & 22.9 & $1.19, \mathrm{~d}(7.0)$ & 23.0 & $1.20, \mathrm{~d}(7.0)$ \\
\hline 11 & & & 14.1 & $1.18, \mathrm{~d}(7.0)$ & 14.1 & $1.19, \mathrm{~d}(7.0)$ \\
\hline
\end{tabular}

Measured on a $500 \mathrm{NB}$ CL NMR spectrometer (Varian, Palo Alto, CA, USA) at $500 \mathrm{MHz}$ for ${ }^{1} \mathrm{H}$ and $125 \mathrm{MHz}$ for ${ }^{13} \mathrm{C}$ with the residual solvent peak as the internal standard $\left(7.25 \mathrm{p} . \mathrm{p} . \mathrm{m}\right.$. for ${ }^{1} \mathrm{H}$ and 77.0 p.p.m. for ${ }^{13} \mathrm{C}$ in $\mathrm{CDCl}_{3}$ ).

averlapped with other signals.

$\left(\delta_{\mathrm{H}} 2.27,2.22\right)$ and an oxygenated methine proton $\mathrm{H}-9^{\prime}\left(\delta_{\mathrm{H}} 3.84\right)$ was established. HMBC correlations from $\mathrm{H}-2^{\prime}, \mathrm{H}-3^{\prime}, \mathrm{H}-11^{\prime}$ and $\mathrm{H}-3$ to an ester carbonyl carbon $\mathrm{C}-1^{\prime}\left(\delta_{\mathrm{C}} 175.2\right)$ were indicative of the direct connectivity between $\mathrm{C}-1^{\prime}$ and $\mathrm{C}-2^{\prime}$ and the presence of an ester linkage between C-3 and C-1'. Therefore, the gross structure of 2 was established as shown in Figure 1. The geometries of the double bonds $\left(\mathrm{C}-4^{\prime}\right.$ and $\left.\mathrm{C}-6^{\prime}\right)$ were deduced as $4^{\prime} E$ and $6^{\prime} E$ based on the large vicinal coupling constants between $\mathrm{H}-4^{\prime}$ and $\mathrm{H}-5^{\prime}$, and $\mathrm{H}-6^{\prime}$ and $\mathrm{H}-\mathrm{7}^{\prime}$ ( $15.0 \mathrm{~Hz}$ and $15.0 \mathrm{~Hz}$, respectively).

The $1 \mathrm{D}$ and 2D NMR spectra of 3 were quite similar to those of 2 , except for the signals corresponding to the C-7, C-11, C-12 and C-13 positions. In the CT-HMBC spectrum of 3 , allylic methyl protons $\mathrm{H}_{3}$ $12\left(\delta_{\mathrm{H}} 2.16\right)$ and $\mathrm{H}_{3}-13\left(\delta_{\mathrm{H}} 1.88\right)$ were long-range coupled to each other and both were also coupled to olefinic carbons C-7 $\left(\delta_{\mathrm{C}} 126.8\right)$ and C-11 $\left(\delta_{\mathrm{C}} 146.3\right)$ (Figure 2e). The assignments of the gem-methyl groups $\mathrm{C}-12$ and $\mathrm{C}-13$ were determined by NOESY correlations among H-13, H-14 and Ha-6 (Figure 2f). Given these, the planar structure was determined as shown in Figure 1. The relative configuration of the sesquiterpenoid moiety of $\mathbf{3}$ was established in the same manner as that of 1 . The large ${ }^{3} J_{\mathrm{H}-3, \mathrm{H}-4}(9.0 \mathrm{~Hz})$ showed the pseudodiaxial relationship between $\mathrm{H}-3$ and $\mathrm{H}-4$. NOESY correlations between $\mathrm{H}-4$ and Hb-6 $\left(\delta_{\mathrm{H}} 2.18\right)$ and between $\mathrm{H}-3\left(\delta_{\mathrm{H}} 5.34\right)$ and $\mathrm{H}-14$ suggested that the $\mathrm{Hb}-6$ and $\mathrm{C}-14$ are in pseudoaxial orientation and are located on the opposite side. Therefore, the partial relative configuration was determined as shown in Figure $2 \mathrm{f}$.

The cytotoxic activities of 1-3 against human ovarian adenocarcinoma SKOV-3 cells were examined by using the WST-8 5-(2,4-
disulfophenyl)-3-(2-methoxy-4-nitrophenyl)-2-(4-nitrophenyl)-2Htetrazolium, monosodium salt] colorimetric assay (Cell Counting Kit; Dojindo, Kumamoto, Japan). After $72 \mathrm{~h}$ of treatment, 1 exhibited moderate cytotoxic activity against SKOV-3 cells with the $\mathrm{IC}_{50}$ of $3.4 \mu \mathrm{m}$. On the contrary, 2 and 3 showed weak cytotoxicity $\left(\mathrm{IC}_{50}=63\right.$ $\mu \mathrm{M}$ and $54 \mu \mathrm{M}$, respectively).

Although eremophilane derivatives have been isolated from many fungal metabolites, ${ }^{2-9}$ to the best of our knowledge, $\mathbf{1}$ is the first example of an eremophilane derivative possessing a tetrahydro- $\alpha$ methyl-5-oxo-2-furanacetic acid moiety.

\section{ACKNOWLEDGEMENTS}

This work was supported by a grant from the New Energy and Industrial Technology Department Organization (NEDO) of Japan, and a Grant-in-Aid for Scientific Research (23380067 to KS) from the Japan Society for the Promotion of Science (JSPS).

1 Tirilly, Y., Kloosterman, J., Sipma, G. \& Bosch, J. J. K. A fungitoxic sesquiterpene from Hansfordia pulvinata. Phytochemistry 22, 2082-2083 (1983).

2 Sugawara, F., Strobel, G., Fisher, L. E., Van Duyne, G. D. \& Clardy, J. Bipolaroxin, a selective phytotoxin produced by Bipolaris cynodontis. Proc. Natl Acad. Sci. USA 82, 8291-8294 (1985).

3 Sugawara, F. et al. Phytoactive eremophilanes produced by the weed pathogen Drechslera gigantea. Biosci. Biotechnol. Biochem 57, 236-239 (1993).

4 Watanabe, N. et al. Bipolal: anti-microalgal compound isolated as a candidate for marine antifouling produced by Bipolaris sp. F5206. J. Nat. Prod 58, 463-466 (1995). 
5 Huang, Y., Qiao, L., Lv, A., Pei, Y. \& Tian, L. Eremophilane sesquiterenes from the marine fungus Penicillium sp. BL27-2. Chin. Chem. Lett. 19, 562-564 (2008).

6 Motohashi, K. et al. New sesquiterpenes, JBIR-27 and -28, isolated from a tunicatederived fungus, Penicillium sp. SS080624SCf1. J. Antibiot. 62, 247-250 (2009).

7 Isaka, M., Srisanoh, U., Sappan, M., Kongthong, S. \& Srikitikulchai, P. Eremophilane and eudesmane sesquiterpenoids and a pimarane diterpenoid from the wood-decay fungus Xylaria sp. BCC 5484. Phytochem. Lett 5, 78-82 (2012).

8 Song, Y. et al. Four eremophilane sesquiterpenes from the mangrove endophytic fungus Xylaria sp. BL321. Mar. Drugs 10, 340-348 (2012).
9 Guerriero, A., Cuomo, V., Vanzanella, F. \& Pietra, F. A novel glyceryl ester (glyceryl dendryphiellate A), a trinor-eremophilane (dendryphiellin A1), and eremophilanes (dendryphiellin E1 and E2) from the marine deuteromycete Dendryphiella salina (Sutherland) PUGHet NICOT. Helv. Chim. Acta 73, 2090-2096 (1990).

10 Kawahara, T., Nagai, A., Takagi, M. \& Shin-ya, K. JBIR-137 and JBIR-138, new secondary metabolites from Aspergillus sp. fA75. J. Antibiot. 65, 535-538 (2012).

11 Furihata, K. \& Seto, H. Constant time HMBC (CT-HMBC), a new HMBC technique useful for improving separation of cross peaks. Tetrahedron Lett 39, 7337-7340 (1998). 